\title{
Oxidative Dehydrogenation of Ethylbenzene Over Poly(furfuryl alcohol)-Derived CMK-1 Carbon Replica
}

\author{
Sebastian Jarczewski ${ }^{1} \cdot$ Marek Drozdek $^{1} \cdot$ Anna Wach $^{1} \cdot$ Barbara Dudek $^{1}$. \\ Piotr Kuśtrowski ${ }^{1}$ - Mirian Elizabeth $\mathrm{Casco}^{2} \cdot$ Francisco Rodríguez-Reinoso $^{2}$
}

Received: 25 March 2016/Accepted: 6 April 2016/Published online: 15 April 2016

(C) The Author(s) 2016. This article is published with open access at Springerlink.com

\begin{abstract}
Poly(furfuryl alcohol) was introduced into a pore system of MCM-48 silica by the precipitation polycondensation of furfuryl alcohol (FA). The complete filling of the pores without the deposition of significant amounts of polymer on the external surface of MCM-48 was obtained at the FA/MCM-48 mass ratio close to 1.0. The final structure of carbon replica was formed by subsequent carbonization and extraction of $\mathrm{SiO}_{2}$ with $\mathrm{HF}$. The
\end{abstract}

carbonization temperature strongly influenced the surface composition of the formed carbon replicas. The highest catalytic activity in the oxidative dehydrogenation of ethylbenzene was observed for CMK-1 with the highest concentration of phenol and carbonyl groups, recognized as active sites of the studied reaction.

\section{Graphical Abstract}

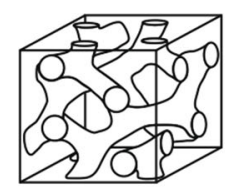

MCM-48

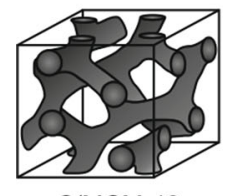

$\mathrm{C} / \mathrm{MCM}-48$
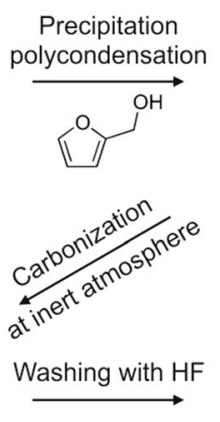

$\stackrel{\text { Washing with } \mathrm{HF}}{\longrightarrow}$

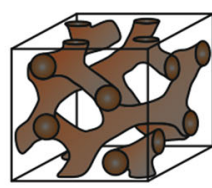

PFA/MCM-48

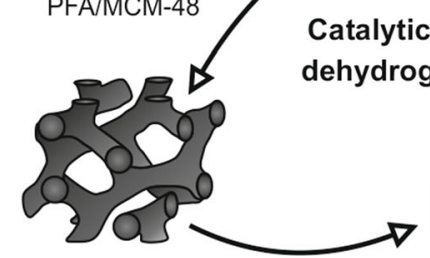

CMK-1
Electronic supplementary material The online version of this article (doi:10.1007/s10562-016-1748-z) contains supplementary material, which is available to authorized users.

\section{Piotr Kuśtrowski}

kustrows@chemia.uj.edu.pl

1 Department of Chemical Technology, Faculty of Chemistry, Jagiellonian University, Ingardena 3, 30-060 Kraków, Poland

2 Laboratorio de Materiales Avanzados, Departamento de Química Inorgánica, Universidad de Alicante, Apartado 99, 03080 Alicante, Spain
Keywords Ordered mesoporous carbons - Replication · CMK-1 - Oxidative dehydrogenation of ethylbenzene . Styrene

\section{Introduction}

Porous carbon materials, especially activated carbons (ACs), offer a variety of prospective applications in catalysis, separation, purification or energy and gas storage [1-8], due to highly developed specific surface area, 
susceptibility to chemical modifications, availability of technologies of large-scale synthesis as well as environmentally friendly character. It was proved that in catalytic applications carbon materials can be used as effective supports of active phase. Moreover, unmodified carbons are active catalysts in many reactions involving oxygencontaining surface functionalities as active sites (e.g. oxidative dehydrogenation of ethylbenzene (ODH), dehydration of alcohols, $\mathrm{SO}_{\mathrm{x}}$ oxidation, $\mathrm{NO}_{\mathrm{x}}$ reduction) [9]. Recently, Yang et al. [10] have described a high catalytic activity of polyacrylamide-based cryogels in the transesterification of fatty glyceride. Furthermore, carbon materials appeared to be effective catalysts in the dehydration of hemicellulosis sugars [11] as well as in the 1,2-dichloroethane (DCE) dechlorination [12]. However, the spatial structure of majority of investigated carbons consists mainly of disordered micropores, which may hinder internal diffusion of reagents during catalytic processes.

Many various carbon structures with an expanded pore system, including graphene-based materials [13] and nanofibers [14], were developed. Among them, ordered mesoporous carbons (OMCs) seem to be ideal candidates to overcome foregoing drawbacks of ACs. These materials exhibit a significant contribution of well-ordered mesopores, which act as wider transport channels for reagents and reduce the diffusion limitations. The main concept of synthesis of OMCs is based on replication of structure of a soft or hard template using a carbon precursor [15]. The soft templating technique includes mixing of a carbon precursor and a pore forming agent (surfactant) to induce the self-assembly process of molecules into micelles generating 3-D structures. Subsequently, polymerization of the carbon precursor is initialized, and the surfactant is eliminated from the obtained composite by carbonization. Unfortunately, the control of pore size, pore wall thickness and pore structure of OMCs produced by the soft-templating method is difficult. On the other hand, these textural parameters can be precisely controlled using the hardtemplating route, but this approach requires a suitable porous material (so called hard template) with a desired pore structure, which is usually synthesized in the first step. After filling the pore system of template followed by carbonization of the formed composite, the template is removed and the carbon replica is obtained.

The CMK-type materials (Carbon Mesostructured by KAIST), developed by Ryoo et al. [16], with various types of carbon mesoporous replicas (e.g. CMK-1, CMK-2, CMK-3 or CMK-6) synthesized using the silica template with the strictly defined pore structure (MCM-48, SBA-1, SBA-15 or SBA-16, respectively) are the most important family belonging to OMCs. The pore architecture of the silica template determines the spatial arrangement of final carbon material and the method of carbon precursor deposition as well. Two methods of introduction of carbon precursor are usually used, i.e. infiltration the silica nanopores with a solution of carbon precursor (i.e. sucrose, furfuryl alcohol or phenolic resin) at ambient temperature or chemical vapor deposition (CVD) performed at elevated temperatures [17].

The CMK-3 replica with hexagonal structure has been extensively studied in various applications which are typical of ACs, whereas other CMK materials have been investigated significantly less often. It should however be believed that CMK-1 (described by Ryoo et al. [18]) can be unappreciated since it exhibits higher specific surface area than CMK-3, which can increase a number of sites exposed on the carbon surface. Moreover, Leżańska et al. [19] showed that more acidic centers can be created on the surface of CMK-1 than CMK-3. The results of recent studies on CMK-1 confirm that this carbon replica is promising in some potential applications, e.g. in dye industry, gas separation or hydrogen storage [20-23].

In the presented work, the synthesis of CMK-1 carbon replicas by precipitation polycondensation of furfuryl alcohol (being the carbon precursor) in the pore system of MCM-48 silica, followed by carbonization of the resulting composite and $\mathrm{SiO}_{2}$ extraction, was developed. The obtained materials were tested as catalysts of ODH, which involves carbonyl/quinone surface groups.

\section{Experimental}

\subsection{Synthesis}

For the MCM-48 synthesis, $32 \mathrm{~mL}$ of cetyltrimethylammonium chloride solution $\left(\mathrm{CTACl}, 25 \mathrm{wt} \%\right.$ in $\mathrm{H}_{2} \mathrm{O}$, Aldrich) was dissolved in a mixture of $134 \mathrm{~mL}$ of distilled water, $210 \mathrm{~mL}$ of methyl alcohol $(\geq 99.8 \%$, SigmaAldrich) and $60 \mathrm{~mL}$ of $25 \%$ ammonium hydroxide solution (Sigma-Aldrich) under vigorous stirring (400 rpm) at room temperature in a round-bottom flask $(500 \mathrm{~mL})$. Subsequently, $18 \mathrm{~mL}$ of tetraethyl orthosilicate (TEOS, $98 \%$, Aldrich) was added dropwise (3 drops/s) and the mixture was stirred at room temperature for $2 \mathrm{~h}$. The resulting solid product was filtered, washed with distilled water $(800 \mathrm{~mL})$ and dried at $60{ }^{\circ} \mathrm{C}$ overnight. Finally, the material was calcined in air atmosphere at $550{ }^{\circ} \mathrm{C}$ for $6 \mathrm{~h}$ (at a heating rate of $1{ }^{\circ} \mathrm{C} / \mathrm{min}$ ).

The prepared MCM-48 material was used as a hard template for the synthesis of CMK-1 replicas, using the modified procedure described by Niebrzydowska et al. [24]. A carbon precursor was deposited in the pores of MCM-48 by precipitation polycondensation of furfuryl alcohol (FA, $98 \%$, Aldrich) in an aqueous slurry of silica, catalyzed by $\mathrm{HCl}$ (35-38 \%, Chempur). The intended PFA/ 
MCM-48 mass ratio of 0.50-2.00 (with a step of 0.25) was controlled by an appropriate amount of FA. The molar ratio of $\mathrm{HCl} / \mathrm{FA}$ was kept constant at 6:1. In a typical procedure, $3 \mathrm{~g}$ of MCM-48 dried initially at $120{ }^{\circ} \mathrm{C}$ for $1 \mathrm{~h}$, was dispersed in a round-bottom flask $(250 \mathrm{~mL})$ containing a mixture of adequate amount of FA and water, to obtain a total mass of $100 \mathrm{~g}$. The flask was equipped with a reflux condenser, placed onto a magnetic stirrer and agitated $(400 \mathrm{rpm})$ at room temperature for $0.5 \mathrm{~h}$. Then, the proper volume of $\mathrm{HCl}$ was added and the temperature was raised up to $100{ }^{\circ} \mathrm{C}$. The obtained slurry was stirred at this temperature for $6 \mathrm{~h}$. The resulting PFA/MCM-48 composite was filtered, washed with distilled water and dried at room temperature overnight. Subsequently, the obtained material was carbonized in a tubular furnace at 650, 750, 850, 950 or $1050{ }^{\circ} \mathrm{C}$ for $4 \mathrm{~h}$ (at a heating rate of $1{ }^{\circ} \mathrm{C} / \mathrm{min}$ ) in an inert atmosphere $\left(\mathrm{N}_{2}\right)$. Finally, the silica template was removed by a treatment with $5 \% \mathrm{HF}$ solution at room temperature for $1 \mathrm{~h}$. The produced carbon replica was filtered, washed with distilled water and ethyl alcohol (96\%, Avantor) and dried at room temperature overnight. The procedure of silica dissolution was repeated once. The samples before and after carbonization at $850{ }^{\circ} \mathrm{C}$ are denoted as PFA_ $x / \mathrm{MCM}-48$ and C_ $x / \mathrm{MCM}-48$, respectively, whereas CMK-1 replicas are marked as $y_{-} \mathrm{CMK}$ 1_ $x$ (where $x$ is the intended PFA/MCM-48 mass ratio and $y$ is the temperature of carbonization).

\subsection{Characterization}

Powder X-ray diffraction (XRD) measurements were performed on a Bruker D2 Phaser instrument using $\mathrm{Cu} \mathrm{K} \alpha$ radiation $(\lambda=1.54184 \AA$ ) and a LYNXEYE detector in the $2 \theta$ range from 0.5 to $8.0^{\circ}$ with a step of $0.02^{\circ}$ and $1 \mathrm{~s}$ counting time per the step. The structure of MCM-48 and CMK-1 materials was also investigated with transmission electron microscopy (TEM). Prior to the experiment, the samples were deposited on a copper grid with a carbon film support. The images were collected with a JOEL JEM2010 microscope equipped with an Oxford Inca Energy TEM 100 detector and a Gatan Orius SC600 digital camera, operating at $200 \mathrm{kV}$.

Nitrogen adsorption-desorption isotherms were measured at $-196{ }^{\circ} \mathrm{C}$ using a Micromeritics ASAP 2020 sorptometer. Prior to the measurement, a sample was degassed in vacuum at $350{ }^{\circ} \mathrm{C}$ for $5 \mathrm{~h}$. The specific surface areas were calculated using the Brunauer-Emmett-Teller (BET) method. The pore size distributions of PFA/MCM48 composites and CMK-1 replicas were calculated using non-local density functional theory (NLDFT) and quenched solid density functional theory (QSDFT), respectively. The values of total pore volumes were obtained from the amount of adsorbed nitrogen at the relative pressure of 0.99 . The mesopore volumes were calculated using the $\mathrm{BJH}$ model from the adsorption branch of the isotherm, whereas the micropore volumes were computed using the t-plot theory.

Thermogravimetric analyses (TG) were performed with a SDT Q600 thermobalance (TA Instruments) in flowing air $(100 \mathrm{~mL} / \mathrm{min})$ from $30{ }^{\circ} \mathrm{C}$ up to $1000{ }^{\circ} \mathrm{C}$ (at a heating rate of $20^{\circ} \mathrm{C} / \mathrm{min}$ ).

The surface composition of samples was investigated with X-ray photoelectron spectroscopy (XPS) using a Prevac photoelectron spectrometer equipped with a hemispherical analyzer (VG SCIENTA R3000). The spectra were taken using a monochromatized aluminum source $\mathrm{Al}$ $\mathrm{K} \alpha(E=1486.6 \mathrm{eV})$. The base pressure in the analytical chamber was $5 \times 10^{-9}$ mbar. The binding energy scale was calibrated using the $\mathrm{Au} 4 \mathrm{f}_{7 / 2}$ line of a cleaned gold sample at $84.0 \mathrm{eV}$. The surface composition was analyzed taking into account the areas and binding energies of $\mathrm{C} 1 \mathrm{~s}$ and $\mathrm{O} 1 \mathrm{~s}$ core levels. The spectra were fitted using CasaXPS software.

Temperature-programmed desorption (TPD) was performed to determine the nature and total amount of oxygen-containing surface functionalities of CMK-1 carbon replicas. The experiments were carried out by heating $100 \mathrm{mg}$ of sample placed in a U-shaped microreactor from ambient temperature up to $1000{ }^{\circ} \mathrm{C}$ (at a heating rate of $10{ }^{\circ} \mathrm{C} / \mathrm{min}$ ) under a helium flow $(50 \mathrm{~mL} / \mathrm{min})$. Evolving $\mathrm{CO}$ and $\mathrm{CO}_{2}$ were analyzed quantitatively with an Omnistar Balzer MSC200 quadrupole mass spectrometer after calibration based on calcium oxalate $\left(\mathrm{CaC}_{2} \mathrm{O}_{4} \cdot \mathrm{H}_{2} \mathrm{O}\right)$ decomposition. The deconvolution of $\mathrm{CO}$ and $\mathrm{CO}_{2}$ profiles was performed by using multiple Gaussian functions with non-linear optimization procedure based on the Levenberg-Marquardt iteration algorithm.

\subsection{Catalytic Tests}

The CMK-1 carbon replicas were tested as catalysts in the oxidative dehydrogenation of ethylbenzene $(\mathrm{EB})$ to styrene in the presence of oxygen at a molar ratio of $\mathrm{O}_{2}: \mathrm{EB}=1: 1$. The reaction was carried out in a packed bed flow microreactor with $50 \mathrm{mg}$ of a sample placed onto a quartz wool plug. The temperature was measured with a thermocouple, protected by a quartz capillary inserted directly into a catalyst bed. The gaseous reactants were fed through mass flow controllers (Brooks 4800) at a total flow rate of $50 \mathrm{~mL} / \mathrm{min}$. EB vapor was introduced into the flow of $\mathrm{He}$ $(49.6 \mathrm{~mL} / \mathrm{min})+\mathrm{O}_{2}(0.4 \mathrm{~mL} / \mathrm{min})$ mixture by passing it through a glass saturator filled with liquid $\mathrm{EB}$ and kept at $25{ }^{\circ} \mathrm{C}$. The products of the reaction were sampled with a pneumatic valve and transferred into a gas chromatograph system (Bruker 450-GC) via a heated line. The gas chromatograph was equipped with three packed columns 
(Porapak Q, Molecular Sieve 5A and Chromosorb W-HP) connected with two flame ionization detectors (one of them directly connected to a catalytic methanizer) and one thermal conductivity detector. Prior to a catalytic run, a sample was outgassed at $200{ }^{\circ} \mathrm{C}$ in flowing $\mathrm{He}(50 \mathrm{~mL} /$ $\mathrm{min}$ ) for $30 \mathrm{~min}$. Subsequently, the temperature of catalyst was increased up to $350{ }^{\circ} \mathrm{C}$ and dosing of reactants begun. After 15 min time-on-stream, the first sample of outlet stream was injected to GC and the analysis started. The chromatographic analyses were performed in $42 \mathrm{~min}$ intervals with a total time of $7 \mathrm{~h}$. The catalyst performance was evaluated in terms of ethylbenzene conversion, yield of styrene and selectivity to particular products according to the following equations:

$$
\begin{aligned}
X_{E B} & =\left(\left(F_{E B, 0}-F_{E B}\right) /\left(F_{E B, 0}\right)\right) \times 100 \% \\
Y_{i} & =\left(F_{i} / F_{E B, 0}\right) \times 100 \% \\
S_{i} & =\left(Y_{i} / X_{E B}\right) \times 100 \%
\end{aligned}
$$

where $X_{E B}$, conversion of ethylbenzene; $F_{E B, 0}$ and $F_{E B}$, molar flow rate of EB in the inlet and outlet streams; $Y_{i}$, yield of $i$ product; $F_{i}$, molar flow rate of EB transformed into $i$ product, $S_{i}$, selectivity of $i$ product.

\section{Results and Discussion}

\subsection{Pore Filling in Mesoporous MCM-48}

In order to determine the efficiency of poly(furfuryl alcohol) deposition in the MCM-48 pore system, thermogravimetric measurements were performed. During the TG analysis, the introduced PFA was completely oxidized. Therefore, the determined mass of remaining silica template allowed to calculate the contribution of organic part in the PFA/MCM-48 composites after subtraction of mass loss attributed to desorption of physically adsorbed water (observed below $200{ }^{\circ} \mathrm{C}$ ). The comparison between the intended and real PFA/MCM-48 mass ratios is presented in Fig. 1. It should be noticed that the estimated efficiency of PFA precipitation is almost constant and equal to ca. $80 \%$ for all synthesized samples. The lower PFA loading than theoretical can be assigned to the formation of PFA oligomers not attached to the silica surface, which were lost during filtration. This explanation was confirmed by yellowish color of the filtrate detected after the polycondensation process. It should be realized that the deposition of polymer in the silica pores was hindered by limited diffusion of the monomer and the catalyst in the highly complex gyroidtype pore structure of MCM-48. Thus, varying location of the formed polymer in the produced composites can also be expected.

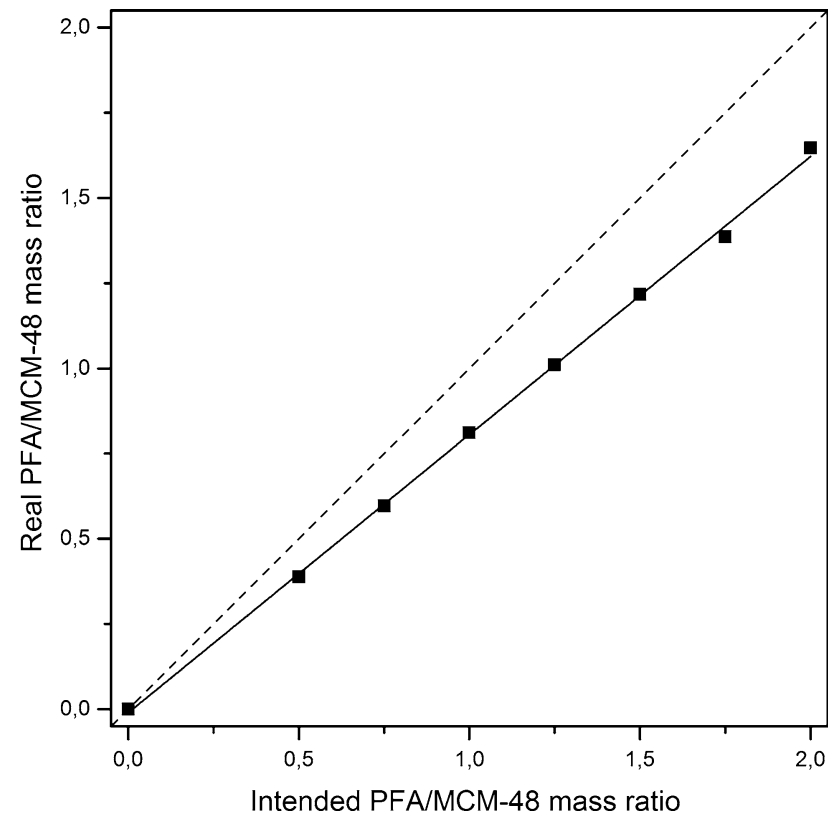

Fig. 1 Efficiency of poly(furfuryl alcohol) deposition in the MCM48 pore system

To investigate these effects, the low-temperature nitrogen adsorption measurements were performed for the neat MCM-48 and the C/MCM-48 materials after carbonization at $850{ }^{\circ} \mathrm{C}$. The collected isotherms are presented in Fig. 2a. A characteristic reversible isotherm of type IV, according to the IUPAC classification, with sharp inflection at relative pressures between 0.15 and 0.35 due to the capillary condensation within uniform mesopores, is observed for the MCM-48 support [25, 26]. In the case of the C/MCM-48 composites, the shapes of isotherms change continuously with increasing the polymer to silica mass ratio, because of carbon precursor fills gradually the pore system. An introduction of higher amount of PFA leads to the change in isotherm shape into type I (according to the IUPAC classification), which is typical of microporous materials [26]. The first inflection at low relative pressures $\left(\mathrm{p} / \mathrm{p}_{0}<0.1\right)$ becomes sharper with the increase in amount of deposited polymer indicating more uniform character of micropores as well as progressive blocking mesopores. As can be seen, the difference between the amount of adsorbed nitrogen for the C_1.00/MCM-48 and C_1.25/MCM-48 samples is insignificant. It is obvious that the carbon precursor gradually clogs the mesopores of MCM-48 with the increasing PFA/MCM-48 mass ratio until their total blockage found for the C_1.25/MCM-48 sample with the real PFA/SiO ${ }_{2}$ of 1.01 .

The pore size distributions (PSD) of the MCM-48 and C/MCM-48 materials calculated using the NLDFT model are shown in Fig. 2b. As expected, a systematic shift of average pore diameter is observed from $34 \AA$ (for mesoporous MCM-48) to lower values (for the C/MCM-48 

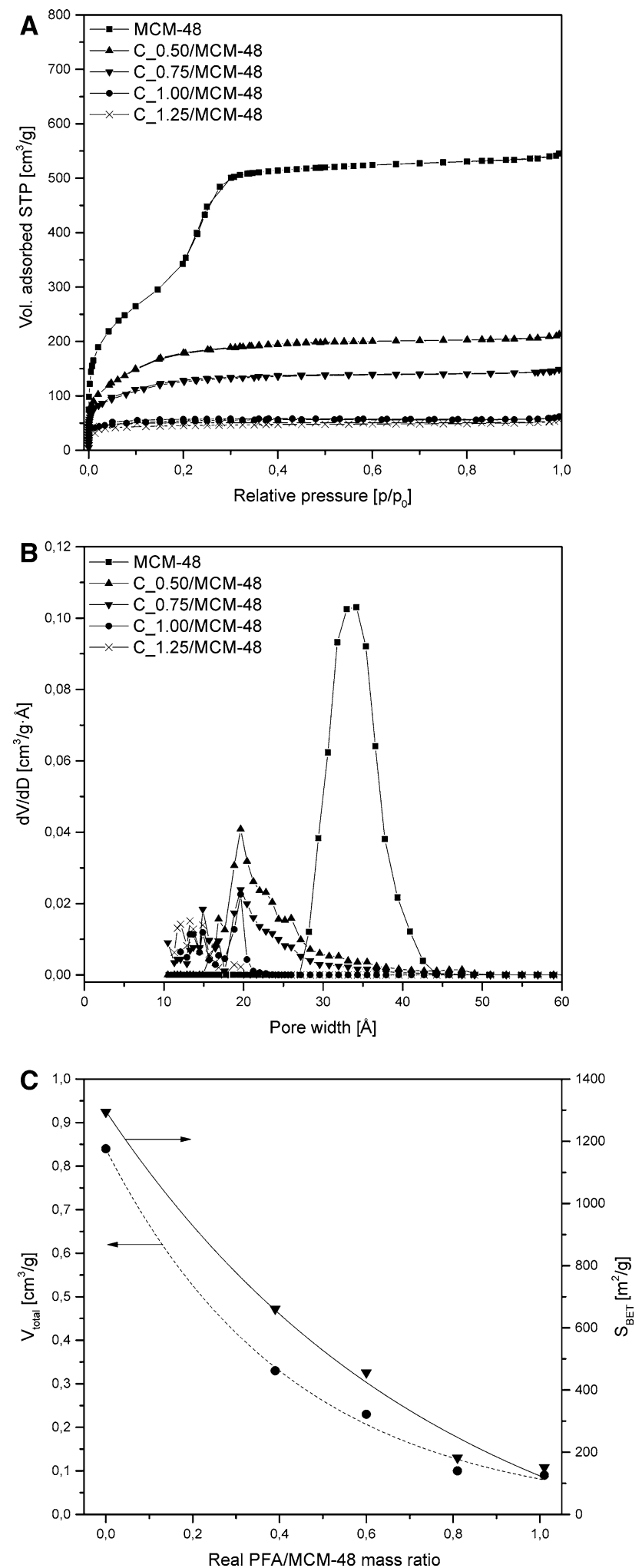

Fig. 2 Low-temperature $\mathrm{N}_{2}$ adsorption isotherms (a), pore size distributions (b) and textural parameters [total pore volumes $\left(\mathrm{V}_{\text {total }}\right)$, specific surface areas $\left.\left(\mathrm{S}_{\mathrm{BET}}\right)\right]$ as a function of real PFA/MCM-48 mass ratio (c) for MCM-48 and the carbon/silica composites composites). Mesoporosity disappears entirely for the C_1.25/MCM-48 sample. Additionally, the samples containing PFA-derived carbon exhibit the presence of micropores, which are most likely formed inside the carbon filler as well as between the carbon rods and silica walls due to the structure shrinkage undergoing during the carbonization process [27].

The textural parameters, i.e. specific surface areas $\left(\mathrm{S}_{\mathrm{BET}}\right)$ and total pore volumes $\left(\mathrm{V}_{\text {total }}\right)$, are depicted in Fig. $2 \mathrm{c}$. It could be noticed that the gradual increase in the amount of PFA deposited in the pores of silica template results in the systematic decrease of $\mathrm{S}_{\mathrm{BET}}$ and $\mathrm{V}_{\text {total }}$, from $1294 \mathrm{~m}^{2} / \mathrm{g}$ and $0.84 \mathrm{~cm}^{3} / \mathrm{g}$ for neat MCM-48, to $151 \mathrm{~m}^{2} / \mathrm{g}$ and $0.09 \mathrm{~cm}^{3} / \mathrm{g}$ for $\mathrm{C}_{-} 1.25 / \mathrm{MCM}-48$, respectively. However, the difference in the $\mathrm{S}_{\mathrm{BET}}$ and $\mathrm{V}_{\text {total }}$ values between the $\mathrm{C}_{-} 1.00 / \mathrm{MCM}-48$ and $C_{-} 1.25 / \mathrm{MCM}-48$ samples is only slight.

Concluding, the specific shape of isotherms, pore diameters as well as textural parameters of $\mathrm{C} / \mathrm{SiO}_{2}$ composites clearly confirm that the complete filling of MCM48 pores with carbon precursor occurs at the real PFA/ MCM-48 mass ratio of about 1.0.

\subsection{Influence of PFA/MCM-48 Mass Ratio on Structural and Textural Properties of CMK- 1 Carbon Replica}

After carbonization at $850{ }^{\circ} \mathrm{C}$ and the removal of silica template with hydrofluoric acid, the resulting CMK-1 replicas were investigated in terms of their textural properties. The isotherms of nitrogen adsorption recorded for the carbon replicas, shown in Fig. 3a, are typical of a CMK-1 material, with a hysteresis loop above $\mathrm{p} / \mathrm{p}_{0}=0.4$ [27]. As can be inferred from the relative position of isotherms, the volume of $\mathrm{N}_{2}$ adsorbed increases constantly, achieving maximum for the CMK-1_1.25 sample. The higher PFA/ MCM-48 mass ratios result in a decrease of amount of $\mathrm{N}_{2}$ adsorbed. The PSD calculated using the QSDFT model are presented in Fig. 3b. Each sample exhibits three different kinds of pores with average diameters centered at about 11 , 17 and $34 \AA$. This clearly confirms that the obtained materials have micro-mesoporous nature. It should however be stressed that the presence of microporosity is typical of carbonized PFA [28, 29]. Furthermore, the CMK-1_1.50, CMK-1_1.75 and CMK-1_2.00 samples show an additional type of pores, with an average pore diameters close to $22 \AA$, which are absent for the samples obtained at the lower PFA/ $\mathrm{SiO}_{2}$ mass ratios. It could be assumed that this porosity might originate from PFA deposited on the external surface of MCM-48.

The total pore volumes and BET surface areas of the synthesized CMK-1 carbon replicas as a function of real 

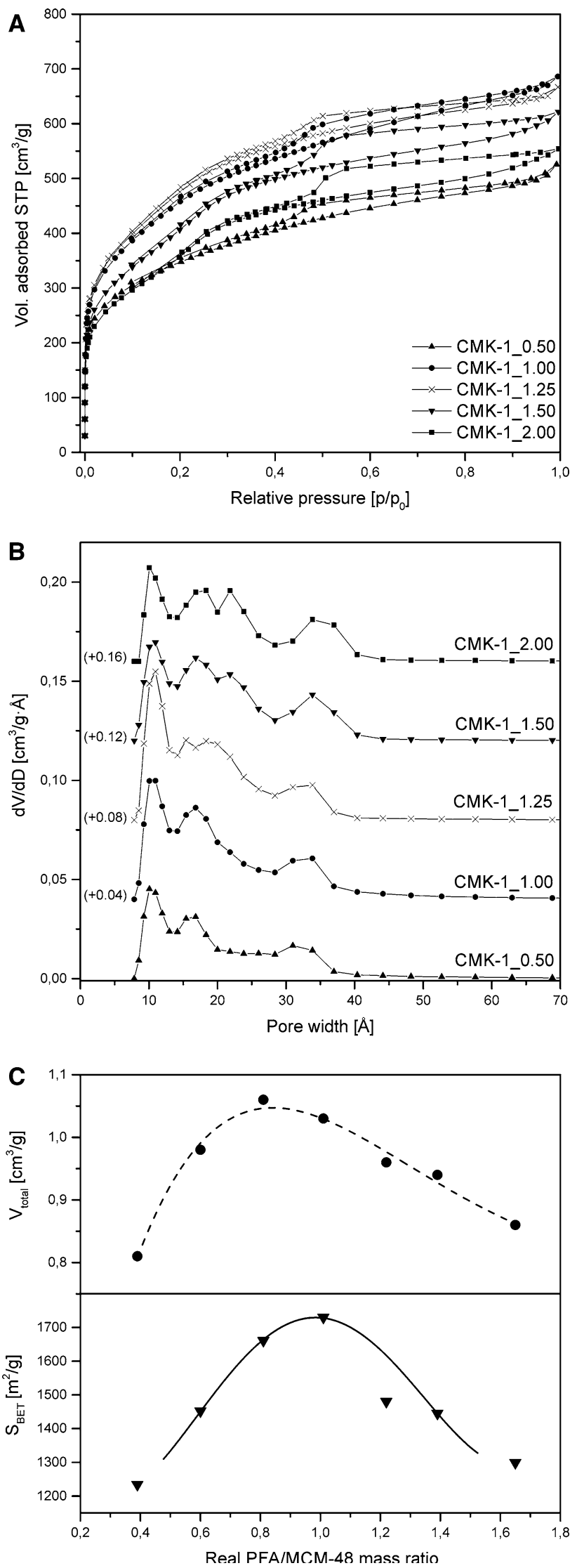

4Fig. 3 Low-temperature $\mathrm{N}_{2}$ adsorption isotherms (a), pore size distributions (b) and textural parameters [total pore volumes $\left(\mathrm{V}_{\text {total }}\right)$, specific surface areas $\left.\left(\mathrm{S}_{\mathrm{BET}}\right)\right]$ as a function of real PFA/MCM-48 mass ratio (c) for the carbon replicas carbonized at $850{ }^{\circ} \mathrm{C}$. The pore size distribution curves of CMK-1_0.50-2.00 were shifted vertically by $0.04,0.08,0.12$ and $0.16 \mathrm{~cm}^{3} / \mathrm{g} \AA$, respectively

PFA/MCM-48 mass ratio are shown in Fig. 3C. $\mathrm{S}_{\mathrm{BET}}$ and $\mathrm{V}_{\text {total }}$ continuously increase with the raising amount of carbon precursor and reach the maximum of $1730 \mathrm{~m}^{2} / \mathrm{g}$ (for CMK-1_1.25) and $1.06 \mathrm{~cm}^{3} / \mathrm{g}$ (for $\mathrm{CMK}_{-} 1.50$ ), respectively. The higher polymer/silica mass ratios lead to a decrease in the value of foregoing parameters, finally to $1299 \mathrm{~m}^{2} / \mathrm{g}$ and $0.86 \mathrm{~cm}^{3} / \mathrm{g}$ for CMK-1_2.00, respectively. The latter effect can be attributed to the additional amount of carbon precursor deposited onto the external surface of MCM-48, which blocks pore system of formed replica after carbonization and silica removal. This is in agreement with the shape of CMK-1_2.00 isotherm, as described above. The same trend can be observed for the $\mathrm{V}_{\text {total }}$ parameter.

The small-angle XRD patterns were collected for MCM48 and CMK-1 replicas carbonized at $850{ }^{\circ} \mathrm{C}$ (cf. Fig. S1 in Supporting Information and Fig. 4, respectively). The XRD pattern of MCM-48 reveals four well defined peaks typical of a gyroid-type structure, which can be indexed as (211), (220), (420) and (332) reflections in the cubic Ia3d space group [30, 31]. The introduction of carbon precursor to the pore system, the subsequent carbonization and the silica removal resulted in an appearance of new diffraction line at about $1.8^{\circ}$. This peak is not characteristic for the Ia3d space group. Thus, the synthesized CMK-1 materials cannot be described as exact replicas of MCM-48. Probably,

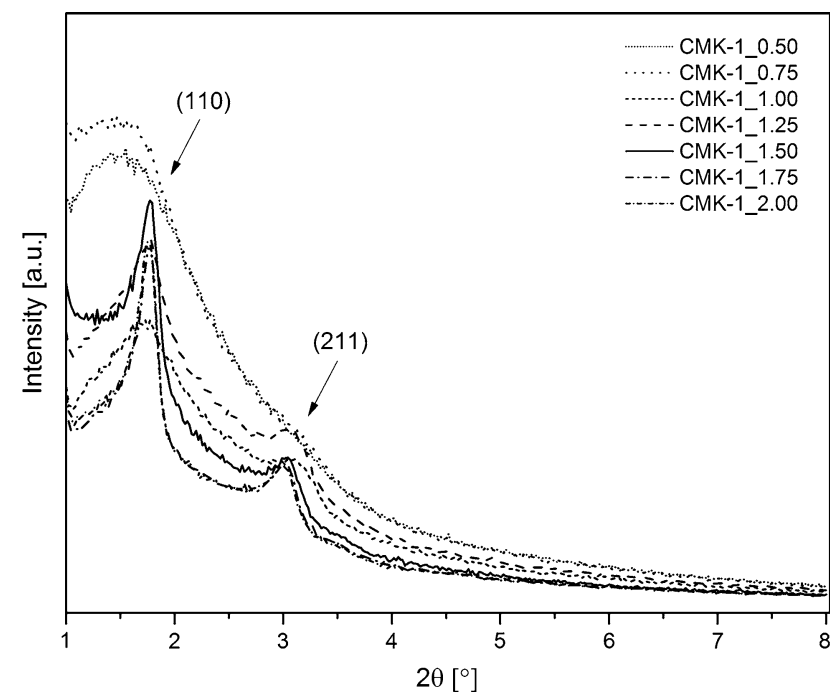

Fig. 4 Low-angle X-ray powder diffraction patterns collected for the CMK-1 carbon replicas carbonized at $850{ }^{\circ} \mathrm{C}$ 

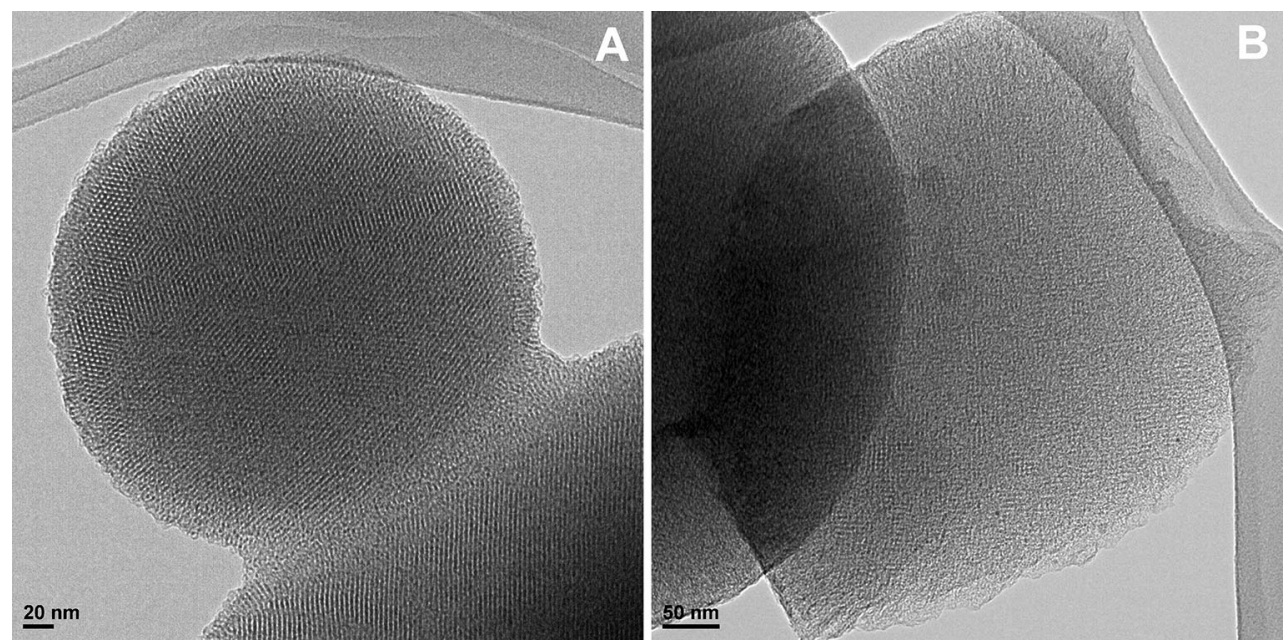

Fig. 5 TEM micrographs for a MCM-48 silica template and b CMK-1_1.25 carbon replica carbonized at $850{ }^{\circ} \mathrm{C}$

the structural transition to another cubic space group $\left(I 4_{1} 32\right)$ occurred, in which the discussed (110) diffraction line appears at $1.77^{\circ}[31]$. Such rearrangement is possible by a slight displacement of two carbon rods relative to each other without rotation along the (001) axis and keeping each rod rigidly.

The CMK-1_1.25 replica obtained at the real PFA/ MCM-48 mass ratio of ca. 1.00, conclusively turned out to have optimal textural and structural parameters. When the PFA/MCM-48 mass ratio is lower, the amount of carbon precursor is insufficient to fill completely the pore system of silica template. Consequently, the spatial structure of carbon replica is weak and has tendency to collapse. On the other hand, exceeding the optimal PFA/MCM-48 mass ratio results in the formation of additional PFA deposited outside the pore system of silica template. After carbonization, it blocks the pores of produced carbon replica.

The TEM micrographs of neat MCM-48 and CMK$1 \_1.25$ carbonized at $850{ }^{\circ} \mathrm{C}$ are demonstrated in Fig. 5. It can be noticed that both samples exhibit an uniform pore distribution and a regular arrangement of mesopores [18, 31]. Furthermore, the thin edges of CMK-1 reveal the absence of carbon deposited on the external surface of replica particles [18]. This evidently confirms that the CMK-1_1.25 sample exhibits the proper structure, which was expected to be synthesized.

\subsection{Influence of Thermal Treatment Conditions on Texture and Surface Composition of CMK-1 Carbon Replica}

The nitrogen adsorption-desorption isotherms collected for the CMK-1_1.25 carbon replica carbonized at different temperatures $\left(650,750,850,950\right.$ or $\left.1050{ }^{\circ} \mathrm{C}\right)$ are shown in Fig. 6A, whereas the corresponding PSD calculated according to the QSDFT model are presented in Fig. 6B. All isotherms exhibit a similar shape with hysteresis loop above $\mathrm{p} / \mathrm{p}_{0}=0.4$, which has been found previously for CMK-1_1.25 calcined at $850{ }^{\circ} \mathrm{C}$. Only isotherm of CMK$1 \_1.25$ calcined at the highest temperature shows clearly higher adsorption at low relative pressures, which suggests the presence of additional micropores. It should therefore be assumed that the carbonization temperature of $1050{ }^{\circ} \mathrm{C}$ was high enough to generate significantly higher microporosity (cf. Table 1). This effect is also confirmed by PSD (Fig. 6B). For all samples three well resolved peaks assigned to the pores with diameters of about 11, 18 and $31 \AA$ can be distinguished. Nevertheless, in the case of the material calcined at $1050{ }^{\circ} \mathrm{C}$ a considerably higher volume of micropores is observed.

The presence of oxygen-containing surface functionalities on the surface of CMK-1_1.25 replica carbonized at different temperatures was studied by temperature-programmed desorption. The lines at $\mathrm{m} / \mathrm{z}=28$ and 44 allowed to observe decomposition of surface groups into $\mathrm{CO}$ and $\mathrm{CO}_{2}$, respectively. The obtained TPD profiles (cf. Fig. S2 in Supporting Information) give information on the type of these species and their relative content. Phenols and carbonyl/quinone groups decompose forming $\mathrm{CO}$ at high temperatures, whereas $\mathrm{CO}_{2}$ appears as a product of decomposition of carboxylic groups in the low-temperature range and/or anhydrides/lactones at higher temperatures [2, 9, 32-35]. Accordingly, in the case of $\mathrm{CO}$ evolution, two high-temperature peaks can be recognized in the TPD profiles, in the temperature ranges of 630-685 and $775-825^{\circ} \mathrm{C}$, which can be assigned as phenol and carbonyl functional groups, respectively [2, 9, 32-35]. Furthermore, in the $\mathrm{CO}_{2}$ profiles, three peaks can be distinguished in the temperature ranges of $260-285,515-565$ and $615-670{ }^{\circ} \mathrm{C}$ corresponding to decomposition of carboxylic, anhydrides 

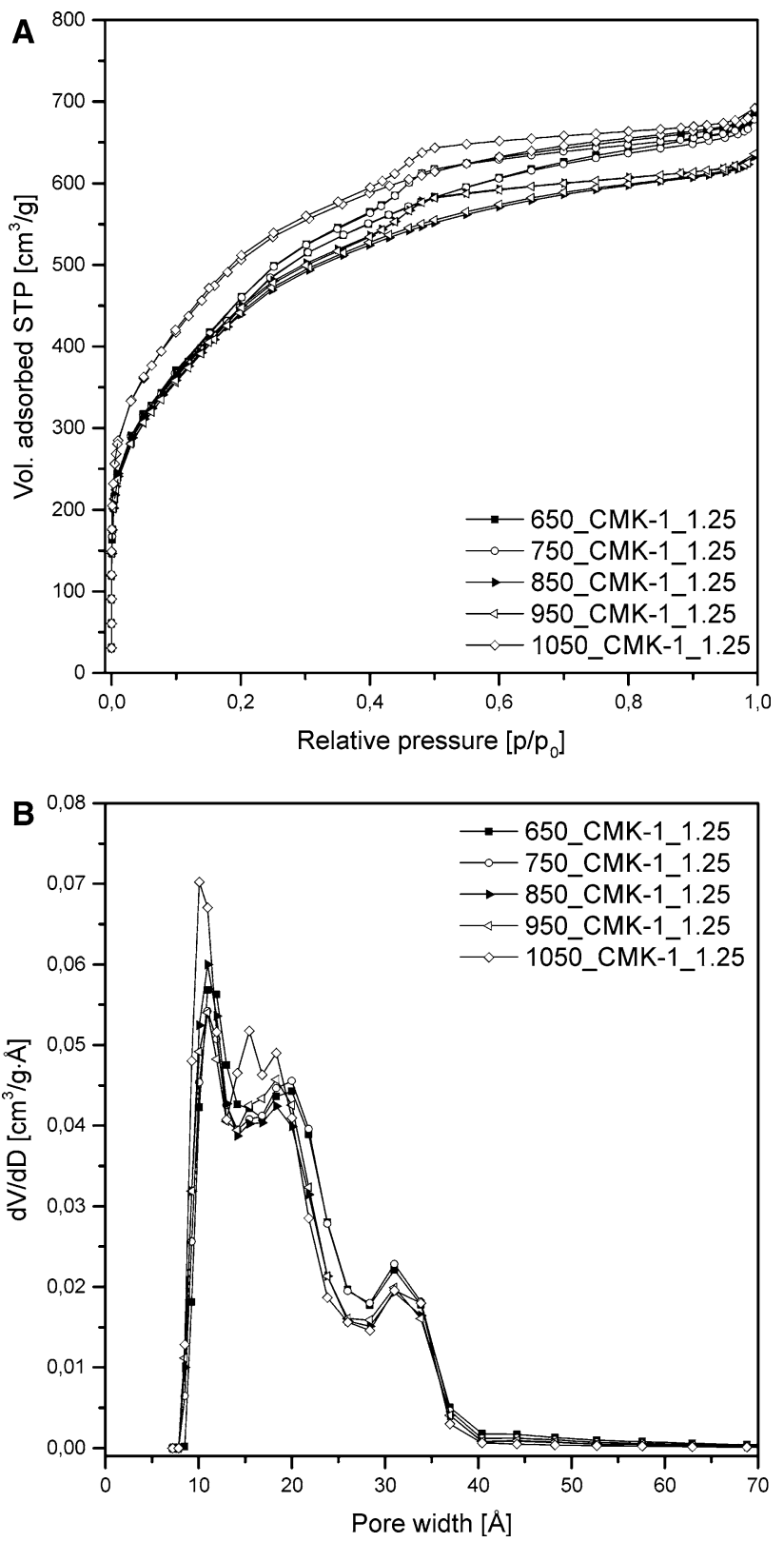

Fig. 6 Low-temperature $\mathrm{N}_{2}$ adsorption isotherms (a) and pore size distributions (b) for the CMK-1_1.25 replicas carbonized at different temperatures

and lactones, respectively. To estimate the content of each type of surface groups, the $\mathrm{CO}$ and $\mathrm{CO}_{2}$ profiles were deconvoluted and the areas of particular peaks were calculated. The results of quantitative analysis of surface composition are summarized in Table 2. It is obvious that the content of surface groups, which decompose with the formation of $\mathrm{CO}_{2}$, is significantly lower than those forming $\mathrm{CO}$ due to differences in their thermal stability. The thermal treatment at temperatures $\geq 650{ }^{\circ} \mathrm{C}$ effectively eliminated less stable $-\mathrm{COO}$ - species. On the other hand, even so high carbonization temperatures influence the surface composition. It should be noticed that the concentration of carbonyl groups, considered as the active sites of ODH process, achieves the maximum after carbonization at $750{ }^{\circ} \mathrm{C}$.

The XPS measurements of CMK-1_1.25 provide a further insight into distribution of oxygen-containing groups on the external surface of the materials calcined at different temperatures. The $\mathrm{O} 1 \mathrm{~s}$ and $\mathrm{C} 1 \mathrm{~s}$ high resolution XPS spectra are presented in Figure S3 in Supporting Information, whereas the determined contents of surface species are collected in Table 3. The $\mathrm{O} 1 \mathrm{~s}$ core level spectrum reveals the existence of two main different oxygen species that can be interpreted as: (1) the double-bonded oxygen atoms in ketones, esters and acids at lower binding energies (530.6-531.1 eV), and (2) the single-bonded oxygen in alcohols, ethers, esters and acids at higher binding energies $(532.7-533.2 \mathrm{eV})[36,37]$. Additionally, the contribution from oxygen in adsorbed water is also considered in the fitting procedure. The presence of these groups was also confirmed by the $\mathrm{C} 1 \mathrm{~s}$ core level spectra. The main contribution to the $\mathrm{C} 1 \mathrm{~s}$ photoelectron spectra is an asymmetric peak with an exponential tail centered at $284.4 \pm 0.1 \mathrm{eV}$. This main peak represents carbon atoms in graphitic and disordered carbon species $\left(\mathrm{C}=\mathrm{C} s p^{2}\right.$ and C-C $s p^{3}$ ) [38]. The polyaromatic character of carbon replicas was furthermore confirmed by the presence of signal above $290.0 \mathrm{eV}$, which corresponds to shake-up satellite due to $\pi-\pi^{*}$ transitions in aromatic rings. In addition, the components due to oxidized carbon species were identified at $286.3( \pm 0.1), 287.4( \pm 0.1)$ and 288.5 $( \pm 0.1) \mathrm{eV}$, which can be assigned to $\mathrm{C}-\mathrm{OH} / \mathrm{C}-\mathrm{O}-\mathrm{C}, \mathrm{C}=\mathrm{O}$ and $\mathrm{COOH}$, respectively $[33,37]$.

The XPS analysis reveals the influence of carbonization temperature on the composition of uppermost, superficial surface layers. The data presented in Table 3 confirm the dominant role of phenol and carbonyl groups among the
Table 1 Textural parameters of the CMK-1_1.25 replicas carbonized at different temperatures

\begin{tabular}{lllll}
\hline Sample & $\mathrm{S}_{\text {BET }}\left(\mathrm{m}^{2} / \mathrm{g}\right)$ & $\mathrm{V}_{\text {micro }}\left(\mathrm{cm}^{3} / \mathrm{g}\right)$ & $\mathrm{V}_{\text {meso }}\left(\mathrm{cm}^{3} / \mathrm{g}\right)$ & $\mathrm{V}_{\text {total }}\left(\mathrm{cm}^{3} / \mathrm{g}\right)$ \\
\hline 650_CMK-1_1.25 & 1633 & 0.15 & 0.65 & 1.06 \\
750_CMK-1_1.25 & 1653 & 0.14 & 0.63 & 1.05 \\
850_CMK-1_1.25 & 1617 & 0.22 & 0.53 & 0.98 \\
950_CMK-1_1.25 & 1635 & 0.21 & 0.53 & 0.98 \\
1050_CMK-1_1.25 & 1861 & 0.33 & 0.50 & 1.07 \\
\hline
\end{tabular}


Table 2 Temperatures of maxima of deconvoluted TPD profiles $\left(\mathrm{T}_{\mathrm{M}}\right)$ and the amounts of identified oxygen-containing surface groups (A) for the CMK-1_1.25 replicas carbonized at different temperatures

\begin{tabular}{|c|c|c|c|c|c|c|c|c|c|c|}
\hline \multirow[t]{3}{*}{ Sample } & \multicolumn{4}{|l|}{$\mathrm{CO}$} & \multicolumn{6}{|l|}{$\mathrm{CO}_{2}$} \\
\hline & \multicolumn{2}{|c|}{ Phenol } & \multicolumn{2}{|c|}{ Carbonyl/quinones } & \multicolumn{2}{|c|}{ Carboxylic } & \multicolumn{2}{|c|}{ Anhydride } & \multicolumn{2}{|c|}{ Lactone } \\
\hline & $T_{M}^{\mathrm{a}}$ & $A^{\mathrm{b}}$ & $T_{M}^{\mathrm{a}}$ & $A^{\mathrm{b}}$ & $T_{M}^{\mathrm{a}}$ & $A^{\mathrm{b}}$ & $T_{M}^{\mathrm{a}}$ & $A^{\mathrm{b}}$ & $T_{M}^{\mathrm{a}}$ & $A^{\mathrm{b}}$ \\
\hline 650_CMK-1_1.25 & 630 & 546 & 775 & 259 & 277 & 25 & 517 & 24 & 617 & 28 \\
\hline 750_CMK-1_1.25 & 631 & 500 & 791 & 281 & 285 & 35 & 554 & 30 & 671 & 14 \\
\hline 850_CMK-1_1.25 & 663 & 317 & 803 & 258 & 270 & 26 & 563 & 11 & 671 & 7 \\
\hline 950_CMK-1_1.25 & 686 & 320 & 825 & 245 & 283 & 29 & 525 & 14 & 670 & 12 \\
\hline 1050_CMK-1_1.25 & 671 & 141 & 814 & 158 & 260 & 31 & 528 & 12 & 657 & 8 \\
\hline
\end{tabular}

a Temperature of the peak maximum $\left({ }^{\circ} \mathrm{C}\right)$

b Amount of particular surface oxygen functional group ( $\mu \mathrm{mol} / \mathrm{g}$ )

\begin{tabular}{|c|c|c|c|c|c|c|}
\hline \multirow[t]{3}{*}{ Sample } & \multicolumn{6}{|c|}{ Atomic concentration (\%) } \\
\hline & \multicolumn{2}{|c|}{ Oxygen } & \multicolumn{4}{|l|}{ Carbon } \\
\hline & $\mathrm{C}=\mathrm{O}$ & $\mathrm{C}-\mathrm{O}$ & $\mathrm{C}=\mathrm{C} s p^{2}, \mathrm{C}-\mathrm{C} s p^{3}$ & $\mathrm{C}-\mathrm{OH}$, ethers, lactones & $\mathrm{C}=\mathrm{O}$ & $\mathrm{COOH} / \mathrm{COOR}$ \\
\hline 650_CMK-1_1.25 & 0.72 & 2.68 & 80.72 & 2.56 & 0.51 & 0.21 \\
\hline 750_CMK-1_1.25 & 2.41 & 2.91 & 75.25 & 3.53 & 2.10 & 0.31 \\
\hline 850_CMK-1_1.25 & 2.61 & 2.73 & 76.74 & 3.06 & 2.33 & 0.28 \\
\hline 950_CMK-1_1.25 & 1.45 & 2.39 & 77.67 & 2.71 & 1.19 & 0.26 \\
\hline 1050_CMK-1_1.25 & 0.67 & 2.28 & 78.04 & 2.54 & 0.45 & 0.22 \\
\hline
\end{tabular}

Table 3 Surface composition of CMK-1_1.25 carbonized at different temperatures determined by XPS molecule. Finally, the formed hydroquinone groups are reoxidized by oxygen with $\mathrm{H}_{2} \mathrm{O}$ evolution [9, 35, 39-42].

It is observed that over each studied sample the EB conversion decreases exponentially with the reaction time reaching a steady-state after ca. $6 \mathrm{~h}$. The catalyst deactivation can be associated with the accumulation of carbonaceous deposit. However, the coke plays a double role in the ODH catalyst. Firstly, it clogs the pores and limits the accessibility of reactants to the active sites. Secondly, the coke layer alters the chemical composition of the surface [35, 40-42]. Those effects were previously observed in the $\mathrm{ODH}$ reaction over the acidic catalysts (such as $\mathrm{SiO}_{2}$, $\mathrm{Al}_{2} \mathrm{O}_{3}$ ) [42, 43] and various carbon materials (ACs, multiwall carbon nanotubes, OMCs) [24, 37, 41, 44].

Figure 8 presents the conversions of ethylbenzene and selectivity to styrene calculated after $6 \mathrm{~h}$ time-on-stream. The similar values of catalytic parameters suggest that the rate of coke deposition is very close, regardless on the surface composition of CMK-1 carbon replica. Nevertheless, the material carbonized at $850{ }^{\circ} \mathrm{C}$ exhibits the highest EB conversion. We have compared the activity and selectivity of this catalyst to the previously tested CMK-3 synthesized by the analogous method and carbonized at the same temperature, described in Ref. [24]. As is shown in Fig. 8, CMK-1 gives slightly higher conversion than CMK3 after $6 \mathrm{~h}$ on-stream time. However, the difference in the selectivity to styrene is much more significant $(98.4 \%$ for 


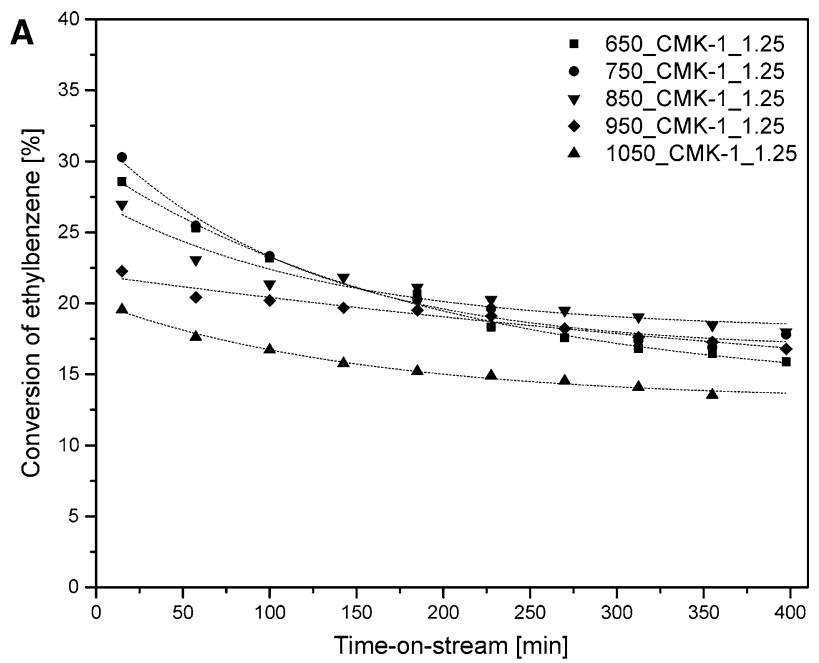

B

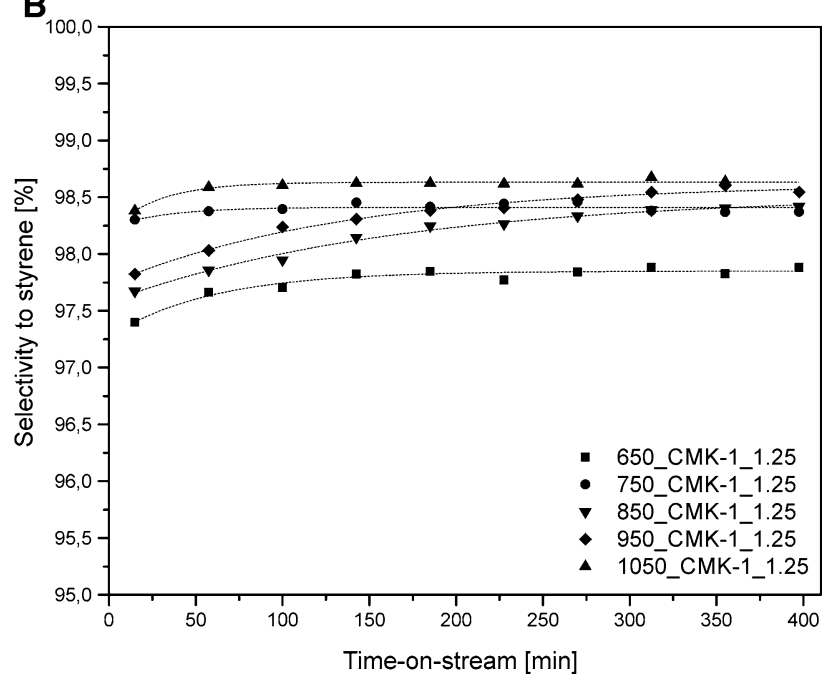

Fig. 7 Conversion of ethylbenzene (a) and selectivity to styrene (b) versus time on stream for the CMK-1_1.25 replicas carbonized at different temperatures

CMK-1 vs. $95.9 \%$ for CMK-3). It should be kept in mind that selectivity to $\mathrm{CO}_{\mathrm{x}}$ is inversely coupled to styrene at negligible selectivity to benzene and toluene [45]. Moreover, it was postulated that the carbonaceous deposit is created by the styrene molecules [41, 43]. It might be stated that the efficiency of the coke deposition affecting the styrene selectivity, depends on the time, in which the styrene molecules stay within the pores of carbon replica. This is due to a higher probability of styrene polymerization with a prolonged residence time. Taking into account the length of channels in the CMK-1 and CMK-3 materials, the shorter residence time can be expected in the case of CMK-1 with the regular pore structure. The straight and long pores of CMK-3 cause the diffusion limitations and favor the coking process lowering the selectivity to styrene.
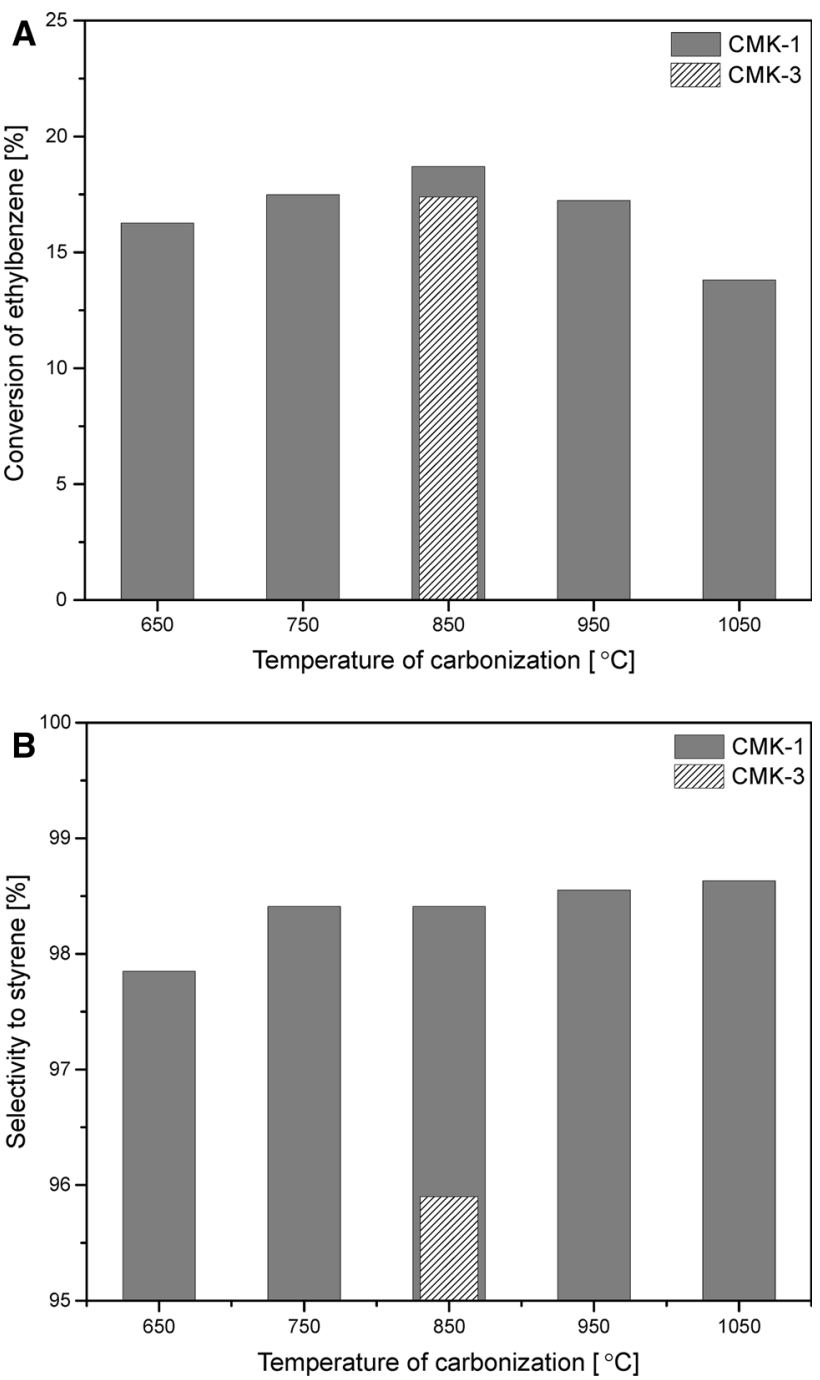

Fig. 8 Conversion of ethylbenzene (a) and selectivity to styrene (b) after $6 \mathrm{~h}$ time-on-stream for the CMK-1_1.25 replicas carbonized at different temperatures compared to the catalytic performance of CMK-3 sample (patterned columns) carbonized at $850{ }^{\circ} \mathrm{C}$ [24]

\section{Conclusions}

Poly(furfuryl alcohol) was successfully deposited in the pore system of regularly ordered MCM-48 mesoporous silica by the precipitation polymerization in the presence of $\mathrm{HCl}$. At the real PFA/MCM-48 mass ratio of about 1.0, complete filling of mesopores by the formed polymer was observed. Carbonization of the obtained composites and the removal of $\mathrm{SiO}_{2}$ resulted in the exposition of structure of CMK-1 carbon replica. It was shown that the pore structure and surface composition of this material depended on the temperature used during carbonization. The increase in this temperature above $1000{ }^{\circ} \mathrm{C}$ favored the formation of additional microporosity in the PFA-derived mesoporous carbon. On the other hand, the elevated 
temperatures caused the elimination of oxygen-containing functionalities present on the surface of replica. The TPD measurements showed that the highest concentration of surface phenol and carbonyl groups was achieved after the thermal treatment at $750{ }^{\circ} \mathrm{C}$. The carbon catalyst carbonized at this temperature was the most active in the oxidative dehydrogenation of ethylbenzene to styrene as well. This observation confirmed the catalytic role of $\mathrm{C}=\mathrm{O}$ species as active centers in the ODH process. Furthermore, CMK-1 showed the slightly higher EB conversion and the significantly higher selectivity to styrene compared to CMK-3, described in the literature. The latter effect can be attributed to the better accessibility of active sites located within the regular pore structure with shorter transport channels than in long, straight pores of hexagonally ordered CMK-3.

Acknowledgments This work was supported by the National Science Centre under the Grant No. 2013/09/B/ST5/03419. The research was carried out with the equipment purchased thanks to the financial support of the European Regional Development Fund in the framework of the Polish Innovation Economy Operational Program (contract No. POIG.02.01.00-12-023/08).

Open Access This article is distributed under the terms of the Creative Commons Attribution 4.0 International License (http://crea tivecommons.org/licenses/by/4.0/), which permits unrestricted use, distribution, and reproduction in any medium, provided you give appropriate credit to the original author(s) and the source, provide a link to the Creative Commons license, and indicate if changes were made.

\section{References}

1. Rodriguez-Reinoso F (1988) Carbon 36:159

2. Figueiredo JL, Pereira MFR, Freitas MMA, Órfão JJM (1999) Carbon 37:1379

3. Yong Z, Mata V, Rodrigues AE (2002) Sep Purif Technol 26:195

4. Yang H, Xu Z, Fan M, Gupta R, Slimane RB, Bland AE, Wright I (2008) J Environ Sci 20:14

5. Xu W-C, Takahashi K, Matsuo Y, Hattori Y, Kumagai M, Ishiyama S, Kaneko K, Iijima S (2007) Int J Hydrogen Energy 32:2504

6. Jin H, Lee YS, Hong I (2007) Catal Today 120:399

7. Sircar S, Golden TC, Rao MB (1996) Carbon 34:1

8. Gamby J, Taberna PL, Simon P, Fauvarque JF, Chesneau M (2001) J Power Sources 101:109

9. Serp P, Figueiredo JL (2009) Carbon materials for catalysis. Wiley, New Jersey

10. Yang C, Liu GF, Zhou XL, Liu YR, Wang J, Tian LL, Hu XY, Wang YY (2015) Catal Lett 145:1778

11. Sairanen E, Karinen R, Lehtonen J (2014) Catal Lett 144:1839

12. Tveritinova EA, Zhitnev YN, Kulakova II, Cherkasov N, Maslakov KI, Nesterova EA, Ivanova AS, Savilova SV, Lunin VV (2015) Appl Surf Sci 355:74
13. Hajjar Z, Kazemeini M, Rashidi A, Bazmi M (2015) Catal Lett $145: 1660$

14. Cherkasov N, Savilov SV, Ivanov AS, Egorov AV, Lunin VV, Ibhadon AO (2014) Appl Surf Sci 308:388

15. Zubizarreta L, Iserte R, Llovera P, Gil-Agustí M (2011) Microporous Mesoporous Mater 143:30

16. Ryoo R, Joo SH, Kruk M, Jaroniec M (2001) Adv Mater 13:677

17. Fuertes AB, Nevskaia DM (2003) J Mater Chem 13:1843

18. Ryoo R, Joo SH, Jun S (1999) J Phys Chem B 103:7743

19. Leżańska M, Pietrzyk P, Dudek A, Włoch J (2015) Mater Chem Phys 149-150:539

20. Anbia M, Ghaffari A (2012) Int J Eng (Trans B Appl) 25:259

21. Ghani K, Kiomarsipour N, Jaberi H (2015) Dyes Pigments 122:126

22. Peng X, Cao D, Zhao J (2009) Sep Purif Technol 68:50

23. Juárez JM, Gómez MB, Anunziata OA (2015) Int J Energy Res 39:941

24. Niebrzydowska P, Janus R, Kuśtrowski P, Jarczewski S, Wach A, Silvestre-Albero AM, Rodríguez-Reinoso F (2013) Carbon 64:252

25. Xu J, Luan Z, He H, Zhou W, Kevan L (1998) Chem Mater 10:3690

26. Sing KSW, Everett DH, Haul RAW, Moscou L, Pierotti RA, Rouquérol J, Siemieniewska T (1985) Pure Appl Chem 57(4):603

27. Kruk M, Jaroniec M, Ryoo R, Joo SH (2000) J Phys Chem B 104:7960

28. Mariwala RK, Foley HC (1994) Ind Eng Chem Res 33:607

29. Burket CL, Rajagopalan R, Marencic AP, Dronvajjala K, Foley HC (2006) Carbon 44:2957

30. Kim S, Marand E, Ida J, Guliants VV (2006) Chem Mater 18:1149

31. Kaneda M, Tsubakiyama T, Carlsson A, Sakamoto Y, Ohsuna T, Terasaki O, Joo SH, Ryoo R (2002) J Phys Chem B 106:1256

32. Lázaro MJ, Calvillo L, Bordejé EG, Moliner R, Juan R, Ruiz CR (2007) Microporous Mesoporous Mater 103:158

33. Zhou J-H, Sui Z-J, Zhu J, Li P, Chen D, Dai Y-C, Yuan W-K (2007) Carbon 45:785

34. Szymański GS, Karpiński Z, Biniak S, Świątkowski A (2002) Carbon 40:2627

35. Figueiredo JL, Pereira MFR (2010) Catal Today 150:2

36. Okpalugo TIT, Papakonstantinou P, Murphy H, McLaughlin J, Brown NMD (2005) Carbon 43:153

37. Darmstadta H, Roy C, Kaliaguine S, Choi SJ, Ryoo R (2002) Carbon 40:2673

38. Estrade-Szwarckopf H (2004) Carbon 42:1713

39. Emig G, Hofmann H (1983) J Catal 84:15

40. Pereira MFR, Órfão JJM, Figueiredo JL (1999) Appl Catal A 184:153

41. Pereira MFR, Órfão JJM, Figueiredo JL (2001) Appl Catal A 218:307

42. Cavani F, Trifirò F (1995) Appl Catal A 133:219

43. Cadus LE, Arrua LA, Gorriz OF, Rivarola JB (1988) Ind Eng Chem Res 27:2241

44. Pereira MFR, Figueiredo JL, Órfão JJM, Serp P, Kalck P, Kihn Y (2004) Carbon 42:2807

45. Zarubina V, Talebi H, Nederlof C, Kapteijn F, Makkee M, Melián-Cabrera I (2014) Carbon 77:329 